\title{
MENDEFINISIKAN KOTA INKLUSIF: ASAL-USUL, TEORI DAN INDIKATOR
}

\author{
Defining Inclusive City: Origin, Theories, and Indicators
}

\author{
Arif Maftuhin ${ }^{1}$
}

Diterima: 1 Maret 2017

Disetujui: 31 Mei 2017

\begin{abstract}
Tulisan ini menjawab pertanyaan tentang apa yang disebut kota inklusif dan indikatornya. Secara akademik, nyaris tidak ada studi tentang 'kota inklusif'. Padahal, dalam praktik, sudah banyak daerah yang berusaha menjadi, atau mengklaim diri, sebagai "kota inklusif". Studi dalam artikel ini bersifat literer karena bertujuan menemukan gagasan dan landasan teoretis yang dapat digunakan untuk mendefinisikan "kota inklusif." Karena definisi saja belum cukup, tulisan juga akan mengkaji indikator kota inklusif. Berdasarkan kajian teoretis yang dilakukan, penulis berpendapat ada empat indikator kota inklusif: (i) adanya partisipasi difabel; (ii) adanya upaya pemenuhan hak-hak difabel; (iii) terjaminya aksesibilitas; dan (iv) adanya sikap inklusif warga kotanya.
\end{abstract}

Kata Kunci: kota inklusif, eksklusi sosial, inklusi, difabel, uu penyandang disabilitas

Despite its recent popular use in Indonesia, "inclusive city" as an academic subject has been relatively neglected. The subject is interestingly absent from Indonesian academic journals in relevant studies. While the term has been globally used and discussed, it is used in a significantly different way. The objective of this paper is to propose a concept of "inclusive city" by defining its dimensions and indicators. It is a localized concept to promote a city that promotes, protects, and accommodates the rights of the disabled. To achieve that objective, this literary research seeks to find theoretical base to argue for inclusion of the disabled. Furthermore, it argues for four dimensions of an inclusive city: (i) a full participation of the disabled; (ii) a promotion of the rights of the disabled; (iii) accessibility; and (iv) inclusive attitude of the people. An elaboration of the indicators is provided afterward.

Keywords: inclusive cities, social exclusion, inclusion, persons with disability, Indonesian disabilty act

\section{PENDAHULUAN}

Sejak beberapa tahun terakhir, ide-ide terkait inklusi mulai marak di Indonesia dan di berbagai bidang. Dalam konteks ini, bidang pendidikan adalah yang terdepan dengan konsep "pendidikan inklusif"-nya. Dari aspek kebijakan publik, pendidikan inklusif sudah mendapatkan payung hukum yang kuat mulai dari undang-undang, peraturan pemerintah, peraturan menteri, dan telah dilaksanakan secara nyata di lapangan oleh banyak daerah di Indonesia. Selain pendidikan, sektor lainnya adalah "kawasan inklusif". Dalam cakupan konsep "kawasan inklusif” ini termasuk konsep-konsep semisal "desa inklusi”('Diskusi Desa Inklusi dalam Jagongan Media Rakyat 2016', 2016), "kecamatan inklusi” ('Peringati Hari

\footnotetext{
${ }^{1}$ The State Islamic Universityof Sunan Kalijaga | maftuhin@uin-suka.ac.id
} 
Disabilitas Internasional, Pemkot Canangkan Empat Kecamatan Inklusi', 2015), hingga "kota inklusi” ('Yogyakarta Bertekad Jadi Kota Inklusi', 2016).

Ide desa inklusif digulirkan bersama dengan berlakunya Undang-Undang No. 6 Tahun 2014 tentang Desa. Sedangkan ide "kota inklusif" tampaknya muncul sebagai pengembangan kebijakan di kota-kota yang sebelumnya telah menjalankan program pendidikan inklusif. Dalam konteks ini, beberapa kota telah mencangkan diri sebagai "kota inklusif" atau kota yang siap menjadi "kota inklusif". Kota Surakarta, barangkali yang pertama di Indonesia, mencanangkan diri sebagai "Kota Inklusi” pada tahun 2013 ('Hadi Rudyatmo Mencanangkan "Solo Kota Inklusi”, 2013). Setelah itu, beberapa kota lain menyusul menjadi kota inklusi, seperti Kota Yogyakarta (2015), Kota Padang, Brebes, dan Jember (2016).

Meskipun deklarasi "kota inklusi" sudah bermunculan di berbagai wilayah Indonesia, namun konsep dan kajian akademik tentang kota inklusif masih belum disentuh secara mendalam. Kota-kota yang disebut sebagai kota inklusif belum memiliki konsep yang mapan tentang inklusivitas mereka. "Kota inklusi" di Surakarta, misalnya, lebih terkait dengan pendidikan inklusif daripada "kota inklusif". Hal ini dapat dapat dilihat dari pernyataan para pemangku kepentingan di kota itu yang mengukur kesiapan kota inklusif dari jumlah sekolah yang siap menjadi sekolah inklusi ('Sosialisasi Pendidikan Inklusif Menuju Solo Kota Inklusi', n.d.). Jadi, mungkin yang dimaksud bukan "kota inklusi" tetapi "kota pendidikan inklusi".

Walaupun ada satu dua penelitian terkait akses difabel di dalam layanan perkotaan (Kurniawan, 2014; Suminar, 2015), secara akademik jurnal-jurnal ilmiah di Indonesia juga belum menerbitkan riset-riset terkait "kota inklusi" atau "kota inklusif". Absennya kajian akademik kota inklusif di Indonesia menjadi menarik ketika konsep itu dilacak dalam terma Inggris, inclusive city. Terma ini ternyata sudah banyak digunakan dan ada sejumlah kajian tentang inclusive city di berbagai penjuru dunia. World Bank, misalnya, mempunyai proyek "Inclusive Cities" di berbagai negara, seperti Vietnam, Tanzania, dan Jamaica ('Inclusive Cities', 2015). Beberapa sumber daring, seperti nexcity.org, juga memuat diskusi menarik tentang apa definisi inclusive city ini ('Commentary', 2013). Jadi, apa yang dinamakan sebagai "Inclusive Citiy" dalam diskusi internasional itu?

Kajian akademik tentang inclusive city umumnya muncul dari studi perkotaan dan urbanisasi. Menurut moto inclusivecities.org, kajian ini terkait dengan "addressing Urban Poverty, Reshaping Urban Planning” ('About the Inclusive Cities Project', n.d.). Kajian yang memfokuskan konsep inclusive city dengan masalah-masalah sosial perkotaan dapat dijumpai dalam beberapa studi. Misalnya kajian yang dilakukan oleh Espino yang terkait dengan segragasi sosial yang diakibatkan oleh tata bangunan kota-kota di Amerika Latin dan bagaimana mengatasi segragasi itu untuk mewujudkan "inclusive city" (Espino, 2015). Kajian ini mirip dengan studi yang juga terfokus pada tata bangunan kota dan dampak sosialnya yang dilakukan oleh sejumlah peneliti dalam buku The inclusive city: design solutions for buildings, neighborhoods and urban spaces (Goltsman \& Iacofano, 2007).

Sementara studi yang lebih berfokus pada struktur sosial, bukan fisik, dapat dijumpai dalam sejumlah studi berikut. Tidak tersedianya fasilitas dan layanan pokok bagi orang miskin kota-kota di Asia menjadi masalah dalam buku The Inclusive City: Infrastructure and Public Services for the Urban Poor in Asia (Laquian, Tewari, \& Hanley, 2007). Pembahasan lebih komprehensif dapat dijumpai dalam buku kumpulan dua puluh artikel yang mendiskusikan berbagai masalah sosial kota yang menjadi alasan perlunya diwujudkan inclusive city dalam buku Inclusive City Überlegungen zum gegenwärtigen Verhältnis von Mobilität und Diversität in der Stadtgesellschaft (Behrens, Bukow, Cudak, \& Strünck, 2016). Behrens dkk. membahas masalah-masalah sosial yang bersumber dari politik, kebijakan, diskriminasi gender, eksklusi sosial, hingga pemanfaatan teknologi untuk menciptakan kota yang ramah bagi semua orang. 
Selagi isu gender sudah sedikit dibahas dalam buku Behrens dkk., kajian khusus yang mengaitkan ide inclusive city dengan perempuan dapat dilihat lebih lengkap dalam buku Building Inclusive Cities: Women's Safety and the Right to the City (Whitzman, 2013). Seperti tercermin dari judulnya, Whitzman dan para penulis di buku itu melihat konsep inclusive city sebagai kota yang mendengar aspirasi perempuan, melibatkan dalam pembangunan, dan aman untuk perempuan bergerak dari satu tempat ke tempat lain tanpa rasa was-was. Dengan kata lain inclusive city dalam buku ini adalah "kota ramah perempuan".

Dari sekian banyak studi tentang inclusive city tersebut dapat disimpulkan bahwa mayoritas kajian inclusive city tidak terkait secara khusus dengan isu-isu difabel. Padahal, seperti disebutkan di depan, konsep "kota inklusif" di Indonesia selalu terkait dengan pemenuhan hak-hak difabel sebagaimana konsep pendidikan inklusif juga lebih terkait dengan hak-hak difabel, bukan inklusivitas ras, etnis, atau agama. Satu-satunya artikel yang membahas konsep kota inklusif dengan difabel adalah tulisan Hanson, "The Inclusive City: delivering a more accessible urban environment through inclusive design” (Hanson, 2004). Dalam tulisannya Hanson berpendapat tentang pentingnya inclusive design sebagai jalan untuk mewujudkan kota yang aksesibel bagi para difabel. Ia mengkritik apa yang disebut sebagai "architectural disability", yaitu desain arsitektur yang rancangannya membuat difabel tidak mampu, tidak nyaman, atau tidak aman untuk menggunakannya. Dari segi kebutuhan untuk menemukan sebuah kota inklusif bagi difabel, kritik Hanson ini menarik dan penting. Hanya saja, kontribusi Hanson baru sepotong aspek tentang bagaimana menghilangkan hambatan fisik (physical barriers) agar kota menjadi inklusif. Padahal jika kita bandingkan dengan konsep-konsep yang dikaji secara umum tadi, inclusive city seharusnya lebih dari persoalan fisik.

Di sinilah penulis berharap dapat berkontribusi lewat tulisan berikut ini dengan dua hal: pertama, pentingnya isu inklusivitas difabel secara khusus dan berargumen mengapa difabel harus dibahas secara khusus dalam diskusi inklusivitas sebuah kota; dan kedua, apa saja indikator yang harus dipenuhi oleh sebuah kota untuk menjadi inklusif.

\section{METODE PENELITIAN}

Penelitian ini bersifat literer dan karena itu metode yang digunakan adalah dengan melakukan riset literatur atas sumber-sumber teoretis primer terkait untuk menjawab pertanyaan-pertanyaan terkait dengan konsep "kota inklusif" di Indonesia dan inclusive cities dalam literatur berbahasa asing. Literatur tersebut kemudian dikaji secara cermat untuk menemukan data-data literer relevan yang digunakan untuk mendukung argumen penulis tentang konsep dan indikator kota inklusif.

Argumen berikut penulis susun dengan sistematika sebagai berikut: Pertama, penulis menyajikan asal-usul konsep kota inklusif yang dikaitkan dengan masalah-masalah eksklusi sosial. Kedua, karena dalam literatur tersebut tidak banyak yang membahas hak-hak difabel, penulis berpendapat bahwa penggunaan istilah "kota inklusif" di Indonesia untuk difabel dapat dibenarkan karena difabel adalah kelompok yang paling rentan eksklusi di semua dimensi eksklusi sosial. Ketiga, penulis berpendapat tentang pentingnya mengajukan pendekatan yang komprehensif, yang tidak dibatasi oleh salah satu model disabilitas yang biasanya dianut oleh pemerintah atau gerakan ndifabel. Keempat, penulis menutup argumen dengan menyajikan konsep kota inklusif dan indikatornya dengan mengacu kepada Undang-undang No. 8 tahun 2016 tentang penyandanga Disabilitas. 


\section{PEMBAHASAN}

\section{Asal-usul Inklusivitas: Social Exclusion}

Diskusi-diskusi umum yang terkait kecenderungan eksklusivitas kota dan masalahmasalah sosial yang diakibatkannya sebenarnya sangat sejalan dengan keprihatinan di kalangan gerakan difabel di Indonesia. Tidak lebih dan tidak kurang, diskusi dan gagasangagasan yang muncul itu akan sangat berguna dalam diskusi "kota inklusif" bagi di fabel di Indonesia karena akar masalah yang disorot adalah sama, yaitu social exclusion yang disebabkan oleh berbagai faktor, baik yang bersifat fisik maupun kultural dan sosial. Pesan itu terlihat dalam beberapa definisi "inclusive cities" yang muncul dalam berbagai studi yang disebutkan di pendahuluan tulisan ini.

Menurut definisi nexcity.org, inclusive city adalah:

An inclusive city is one that values all people and their needs equally. It is one in which all residents-including the most marginalized of poor workers-have a representative voice in governance, planning, and budgeting processes, and have access to sustainable livelihoods, legal housing and affordable basic services such as water/sanitation and an electricity supply ('Commentary', 2013).

Definisi ini menempatkan manusia, warga kota, sebagai kata kuncinya dan bahwa kota yang inklusif adalah kota yang secara politik menghargai warganya secara setara, yang miskin didengar suaranya, terlibat dalam proses perencanaan dan penganggaran, dan secara fisik mereka memperoleh akses terhadap layanan dasar bagi kehidupan, seperti perumahan, air bersih, dan listrik.

Proyek inclusive cities yang dikawal World Bank menyebutkan tiga faktor penting untuk membangun sebuah kota inklusif: Pertama, spacial inclusion atau inklusi 'ruang' (fisik) yang meliputi tersedianya infrastruktur pokok sehari-hari berupa perumahan yang layak huni, air bersih, dan sanitasi. Kedua, social inclusion atau inklusi sosial. Sebuah kota inklusif wajib menjamin kesetaraan hak dan partisipasi semua orang, termasuk mereka yang paling termarjinalkan. Eksklusi terhadap mereka terbukti mengakibatkan ketimpangan dan kerusuhan sosial di berbagai kota. Ketiga, economic inclusion atau inklusi ekonomi. Kota inklusif harus mampu menciptakan lapangan pekerjaan dan kesempatan kepada semua warga kota untuk menikmati buah pertumbuhan ekonomi ('Inclusive Cities', 2015).

Supaya lebih baik memahami konsep "inklusif" seperti yang diusung di atas, penting untuk memhami konsep social exclusion. Konsep ini awalnya muncul di Perancis pada tahun 1970an. Saat itu, istilah social exclusion digunakan untuk menggambarkan kondisi kelompok-kelompok marjinal di masyarakat yang tidak memiliki akses terhadap lapangan pekerjaan dan jaminan kesejahteraan (the income safety nets of the welfare state). Les exclus (mereka yang tereksklusi) tidak mendapatkan hak-hak asasi sebagai warga negara, entah karena mereka menjadi korban diskriminasi, seperti kalangan difabel, atau kerena mereka bukan warga negara Perancis dan tinggal di negeri itu sebagai pencari swaka politik. Mereka juga tidak memiliki akses terhadap lembaga-lembaga penting yang mungkin dapat menolong dan menyuarakan kepentingan mereka, seperti serikat dagang atau serikat warga (Pierson, 2010, pp. 7-8) (Pierson, 2010).

Child Poverty Action Group mendefinisikan social exclusion sebagai proses terhalangnya, sebagian atau sepenuhnya, akses terhadap sistem sosial, ekonomi, dan budaya yang menjadi kunci dalam integrasi seseorang di masyarakat. Menurut defnisi ini, sebagian orang ada yang berada di luar lingkaran, tidak dapat berpartisipasi penuh di masyarakat, dan masalah ini bersifat sistematik karena bersumber dari -apapun sebabnya-sistem sosial (Sheppard, 2006, p. 7). Menurut Sheppard, kelompok yang dapat tereksklusi secara sosial diantaranya adalah: (1) Kelompok miskin, penganguran, dan tidak 
beruntung lainnya; (2) Tidak memperoleh pemenuhan haknya sebagai warganegara; dan (3) Mereka yang terputus dari relasi sosialnya (Sheppard, 2006, p. 10).

Sementara itu, the centre for the analysis of Social Exclusion menyatakan bahwa orang dikatakan tereksklusi secara sosial bila: (a) ia secara geografis (bukan KTP) adalah penduduk di suatu wilayah; (b) ia tidak dapat berpartisipasi dalam kegiatan yang lazimnya dilakukan oleh warga di tempat itu, dan (c) ia sangat ingin berpartisipasi, tetapi keinginannya terhalang oleh berbagai faktor di luar kontrol dirinya (Burchardt, Le Grand, \& Piachaud, 1999, p. 227). Definisi ini tegas menekankan bahwa orang tereksklusi ketika ia tinggal di sebuah perkampungan, komunitas, atau negeri tetapi terhalang oleh keadaankeadaan yang di luar kemauan dan kemampuan mereka sendiri. Definisi ini penting dan pantas diangkat karena menekankan bahwa tidak ada orang yang mengeklusikan diri. Orang disebut excluded karena ia memang excluded, berbeda dengan orang yang sengaja mengucilkan diri dengan kemauan sendiri karena satu dan lain hal.

Pierson menyebutkan lima komponen penting dalam eksklusi sosial: (1) kemiskinan; (2) pengangguran; (3) tidak adanya jejaring pendukung sosial; (4) pengaruh tempat tinggal dan lingkungan sosial; (5) terkecualikan dari layanan umum. Ia berpendapat bahwa kelima komponen itu sesungguhnya saling terkait dan saling memperparah eksklusi, sehingga upaya untuk membangun inklusi sosial memerlukan pendekatan dan program multidimensi untuk menangani satu per satu komponen tersebut, semisal peningkatan pendapatan, memperkuat jejaring sosial, meningkatkan kualitas hidup di sebuah kawasan, dan membuat layanan umum yang aksesibel. (Pierson, 2010, p. 13).

\section{Difabel Sebagai Kelompok Rentan Eksklusi}

Tulisan Person tentang lima komponen eksklusi tidak menyebutkan secara spesifik subjeknya. Hanya saja, ketika indikator yang ia buat digunakan untuk mengidentifikasi kelompok rentan ekslusi di dalam masyarakat, akan mudah ditemukan bahwa kelompok difabel adalah salah satu yang paling mungkin terperangkap dalam lima komponen eksklusi sosial. Riset-riset berikut menggambarkan relasi kuat antara eklsusi ini dan difabel.

Pertama, komponen terpenting yang menciptakan eksklusi adalah kemiskinan dan penghasilan yang kecil. Kemiskinan sendiri ada dua macam: kemiskinan absolut yang ditentukan oleh angka tertentu untuk menentukan kemiskinan; dan kemiskinan relatif yang didefinisikan sebagai tidak adanya sumberdaya untuk memenuhi kebutuhan yang dianggap layak dalam sebuah masyarakat. Ada banyak studi yang dengan baik menunjukkan 'lingkaran setan' disabilitas dan kemiskinan ini (Yeo \& Moore, 2003, pp. 572-573). Secara sederhana dapat dikatakan, kemiskinan mengakibatkan gizi buruk pada ibu hamil. Gizi buruk pada gilirannya dapat mengakibatkan disabilitas pada anak yang dikandung. Kemudian, lahirlah anak difabel di keluarga miskin itu. Karena ia difabel dan miskin, maka akses terhadap semua layanan dasar terbatas dan kelak mengakibatkan kesehatannya yang tidak memadai dan seterusnya. Difabilitas melahirkan kemiskinan dan kemiskinan melahirkan difabilitas.

Dalam hal posisi difabel dalam kelompok masyarakat miskin, Wolfensohn berpendapat bahwa:

People with disabilities in developing countries are over-represented among the poorest people. They have been largely overlooked in the development agenda so far, but the recent focus on poverty reduction strategies is a unique chance to rethink and rewrite that agenda. One of the Millennium Development Goals is the eradication of extreme poverty and hunger, a goal that cannot be achieved without taking into consideration a group of people that is so disproportionately represented among the world's poorest people (Eide \& Ingstad, 2011, p. 2). 
Artinya, jika orang ingin berbicara tentang kelompok miskin dan pengentasan kemiskinan, maka nyaris tidak mungkin mengabaikan difabel dalam diskursus itu. Jumlah difabel dalam kelompok masyarakat miskin itu over-represented, terlalu banyak.

Kedua, pengangguran dan akses ke dunia kerja. Karena kondisi fisiknya, difabel adalah kelompok masyarakat yang paling sering mengalami eksklusi di dunia pekerjaan. Sejumlah penelitian di Inggris menunjukkan bahwa (1) 60\% difabel usia kerja tidak bekerja di pekerjaan bergaji (paid work); (2) tingkat pengangguran di kalangan difabel tiga kali lebih tinggi daripada non-difabel; (3) demikian juga waktu tunggu untuk mendapatkan pekerjaan yang lebih lama; sedangkan (4) satu dari enam orang yang mendapatkan pekerjaan, hanya mampu bertahan selama setahun hingga kehilangan pekerjaan lagi dan sepertiga pekerja difabel menganggur lagi setelah setahun; (5) difabel juga memperoleh penghasilan yang jauh lebih rendah dari umumnya pekerja dan 50\% difabel memperoleh pendapat di bawah garis kemiskinan; dan paling menariknya lagi (6) para difabel juga mengalami lebih banyak tidak terserap di lapangan pekerjaan yang seharusnya mereka lebih dari memenuhi syarat (overqualified) untuk bekerja di bidang itu (C Barnes \& Mercer, 2006, pp. 533-534).

Komponen ketiga dari eksklusi sosial adalah lemahnya jaringan sosial yang dimiliki oleh individu, keluarga atau kelompok tertentu dalam masyarakat. "Jaring kemiskinan" biasanya mencegah orang dari memiliki akses kepada kehidupan dan standar kehidupan yang layak dalam sebuah masyarakat. Difabel mengalami eksklusi dari memanfaatkan jejaring sosial karena masih banyaknya keluarga yang tertutup soal anaknya yang difabel hingga menyembunyikan anaknya ('parenting- Hak Anak Difabel', n.d.). Alih-alih memperoleh manfaat dari jejaring sosial, difabel malah semakin terkucil. Mereka yang menyandang disabilitas mental masih banyak mengalami pemasungan di Indonesia ('Setidaknya 18.800 orang masih dipasung di Indonesia', 2016).

Keempat, lingkungan fisik. Menurut Wendell, masyarakat yang secara fisik terstruktur dan secara kelembagaan tertata biasanya dilandasakan pada asumsi-asumsi yang tak disadari/tak diakui bahwa semua orang itu sehat, non-difabel, muda tetapi dewasa, dan berprilaku seperti yang diidealkan. Asumsi-asumsi laten seperti inilah yang seringkali menciptakan disabilitas karena mengabaikan fakta bahwa tidak semua orang mencapai level 'ideal' untuk bisa sepenuhnya menjadi bagian, berpartisipasi, dalam masyarakat (Wendell, 1996, p. 39)

Asumsi-asumsi laten ini pada gilirannya melahirkan pembangunan fisik yang membuat orang menyandang disabilitas. Karena asumsi (yang tidak disadari) bahwa Muslim yang baik adalah yang sehat jasmani dan rohani, maka masjid-masjid dibuat megah meninggi. Karena meninggi, maka dibutuhkan undakan berundak untuk memasuki masjid. Struktur ini lalu membuat pengguna kuris roda menjadi 'disabled' (dibuat tidak mampu). Demikian juga dengan tempat wudu. Karena semua orang diasumsikan melihat, maka stuktur bangunan yang ramah bagi tunanetra diabaikan (Maftuhin, 2014).

Komponen kelima adalah layanan, baik layanan publik maupun swasta. Berbagai penelitian telah menunjukkan bagaimana difabel tereksklusikan dalam layanan publik semacam transportasi. Trotoar di hampir semua kota di Indonesia jarang sekali ramah bagi pengguna kursi roda. Sehingga para pengguna kursi roda tereksklusikan dari partisipasi dalam banyak kesempatan yang memerlukan aksesibilitas di luar rumah. Demikian juga angkutan umum yang belum memenuhi aksesibilitas untuk mengakomodasi kebutuhan mereka.Sedikit demi sedikit, kantor-kantor pemerintahan di Kota Yogyakarta, misalnya, memang telah direnovasi agar ramah difabel. Tetapi, mayoritas bangunan tetap tidak terakses dengan baik.

Korelasi antara social exclusion dan inklusi bagi kaum difabel muncul jelas dalam studi yang didanai oleh the European Commission pada tahun 2001. Penelitian "Disability and Social Exclusion in the EU - time for change, tools for change" menyisir enam bidang layanan publik di berbagai negara Eropa: (1) Kesehatan dan layanan sosial; (2) Layanan 
pemerintahan; (3) Lingkungan Sosial; (4) Transportasi; (5) Informasi; (6) Ketersediaan layanan sosial. Studi ini menunjukkan bagaimana difabel di negara-negara Uni Eropa belum meperoleh akses dan layanan yang layak di berbagai bidang yang dikaji tersebut dan menjadi bagian masyarakat yang paling rentan terhadap eksklusi sosial (The Greek National Confederation of Disabled People, 2002).

Jadi, difabel adalah kelompok yang paling rentan eksklusi sosial dan karena itulah penulis berpendapat bahwa apa yang berkembang di Indonesia dalam konsep "kota inklusif" sangat dapat dipahami. Meski di belahan dunia yang lain konsep "kota inklusif" lebih diartikan sebagai kota yang membuka partisipasi semua orang, pilihan untuk memaknai "kota inklusif" sebagai kota yang ramah difabel lebih dari cukup untuk merepresentasikan kota yang ramah bagi semua orang. Sebab, di antara kelompokkelompok rawan ekslusi sosial, difabel adalah kelompok yang berisiko tertinggi. Katakanlah jika perempuan miskin adalah kelompok yang rawan ekslusi, maka perempuan miskin difabel adalah orang yang paling rentan tereksklusi.

\section{Model-model Disabilitas dan Inklusivitas}

Dalam studi disabilitas, ada sejumlah model disabilitas yang biasanya digunakan untuk menganalisis isu-isu disabilitas. Terkait dengan hal ini, pembaca dapat merujuk ke berbagai tulisan semisal dalam tulisan-tulisan di buku Rethingking Disability (Devlieger, 2003), Disability Studies: An Interdisciplinary Introduction (Goodley, 2011), atau Disability Studies Today (Colin Barnes, Oliver, \& Len, 2002). Karya-karya tersebut sudah secara baik membahas berbagai teori, pendekatan, dan model mutakhir dalam kajian disabilitas. Dalam bagian ini, penulis cukupkan untuk mengevaluasi berbagai model itu dalam kaitannya dengan konsep kota inklusif yang akan diusulkan di bagian berikutnya. Sebab, tidak dapat dipungkiri, berbagai model itu selalu mewarnai pengambilan kebijakan-kebijakan publik terkait dengan difabel. Misalnya, dalam riset terhadap Undang-undang no. 8 tahun 2016, Millati menemukan pengaruh model-model teoretis itu dalam setiap pasal-pasal undangundang (Millati, 2016).

Dalam konteks perumusan konsep kota inklusif, masing-masing model akan melahirkan kebijakan-kebijakan yang khas. Pertama, model kultural dan medis akan menghasilkan kebijakan-kebijakan yang sasaran utamanya adalah 'orang' per 'orang'. Pendekatan kultural, yang berpendapat bahwa disabilitas adalah 'takdir' atau 'karma', menghasilkan kebijakan-kebijakan yang berusaha mengubah individu difabel untuk menerima, untuk berpikir positif tentang keadaan dirinya, dan bahwa Tuhan telah memilihnya untuk menjadi demikian karena punya tujuan. Demikian pula terhadap nondifabel, pendekatan ini akan menghasilkan kebijakan yang menghendaki masyarakat untuk 'mengasihani' difabel dan agar menjadikan hidup mereka sebagai 'cermin untuk bersyukur'.

Sedangkan model medis, sebagaimana sudah banyak dikritik, akan melahirkan kebijakan yang semata-mata rehabilitatif. Seperti pendekatan kultural, pendekatan medis juga menyasar individu, khususnya individu difabel. Karena difabel dikategorikan 'sakit' atau 'cacat', maka kebijakannya adalah 'menormalkan' atau 'menyembuhkan' si individu dari disabilitasnya. Kebijakan-kebijakan pemerintah, melalui kementerian dan dinas sosial, masih banyak dipengaruhi oleh model ini.

Sedangkan model sosial akan melahirkan kebijakan-kebijakan yang, menurut para kritikusnya, 'mengabaikan' kebutuhan dan pengalaman orang per orang difabel karena fokusnya yang diarahkan untuk mengubah struktur sosial. Produk-produk kebijakan yang mengacu ke model sosial dapat dilihat dalam pembuatan trotoar yang ramah kursi roda, dilengkapi dengan guiding block bagi tunanetra, pintu masuk yang lebar, penyediaan akses ramp, mofidifikasi rambu lalu lintas, dll. Dapat dikatakan, ide-ide 'kota inklusif' sendiri, sebagaimana yang berkembang dan muncul selama ini, sebenenarnya banyak dipengaruhi 
dan terinspirasi oleh model sosial. Hal ini dapat dilihat, misalnya, dari rekomendasirekomendasi yang dihasilkan dalam forum Temu Inklusi tahun 2014. Sebagai contoh kasus dapat dilihat dalam rekomendasi bidang ketenagakerjaan. Dari dua belas item yang direkomendasikan, hanya satu item yang mengacu kepada model medis. Selebihnya, sebelas item, adalah daftar kebijakan yang mengacu ke model sosial (Salim, Syafi'i, \& Elisabeth, 2015, p. 116).

Model sosial, terlepas dari para kritikusnya, adalah model yang paling dapat membantu merumuskan kebijakan 'kota inklusif.' Istilah 'kota inklusif' sendiri berasumsi bahwa masalah disabilitas ada di 'kota', bukan pada individu difabel. Dalam model sosial, ada tiga hambatan yang diyakini mengahalangi terwujudnya kota inklusif: sikap (attitudiona), lingkungan (environmental), dan lembaga (institutiona):

Disabled people may be socially excluded by attitudes of fear and ignorance on the part of non-disabled people, who may use negative and pejorative language about them; or they may be excluded from society because of generally low expectations of what disabled people can achieve. Environmental discrimination occurs where public services, buildings, and transport are not designed with access for disabled citizens in mind. Institutional discrimination occurs where the law discriminates (explicitly or by omission) against the rights of disabled people, making them in some way second-class citizens - without the right to vote, to own land, to attend school, to marry and have children (Harris, Enfield, \& Oxfam GB, 2003, p. 11)

Meskipun demikian, penulis berpendapat bahwa untuk membangun sebuah kota inklusif, satu pendekatan saja tidak cukup. Pendekatan satu model akan melahirkan kebijakan yang parsial dan tidak komprehensif seperti dapat diilustrasikan dari gambar berikut:

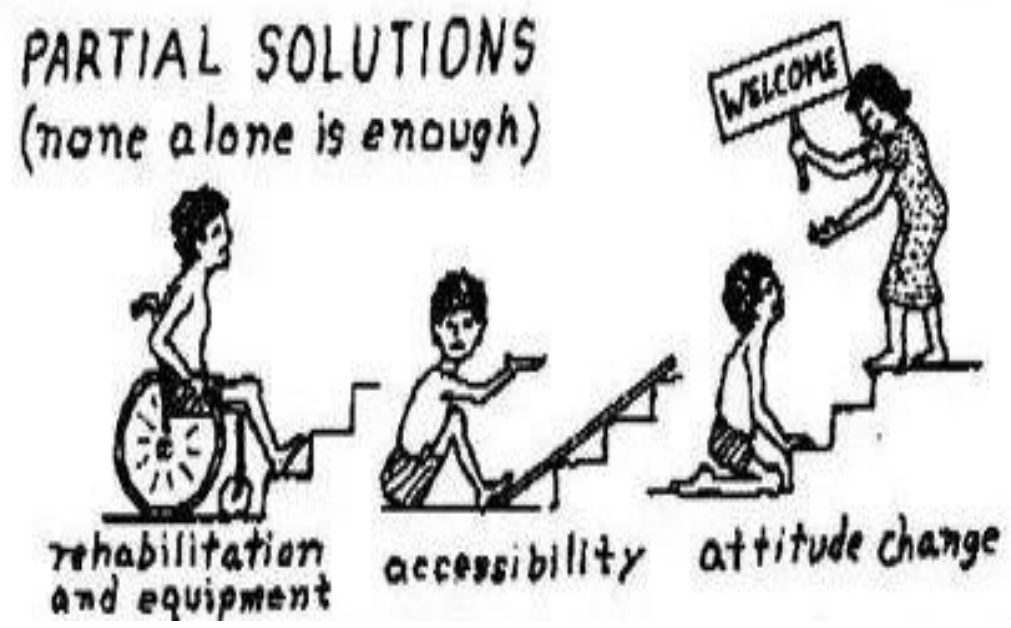

Sumber:('Manual Making PRSP Inclusive: 6.1.1 The four models’, n.d.)

\section{Gambar 1. Solusi Parsial}

Sebagai alternatifnya, maka kota inklusif yang diidealkan oleh makalah ini adalah kota yang melakukan pendekatan komprehensif dengan mendengarkan dan melaksanakan berbagai aspek penting dalam berbagai model difabilitas secara integral, seperti dalam ilustrasi berikut: 


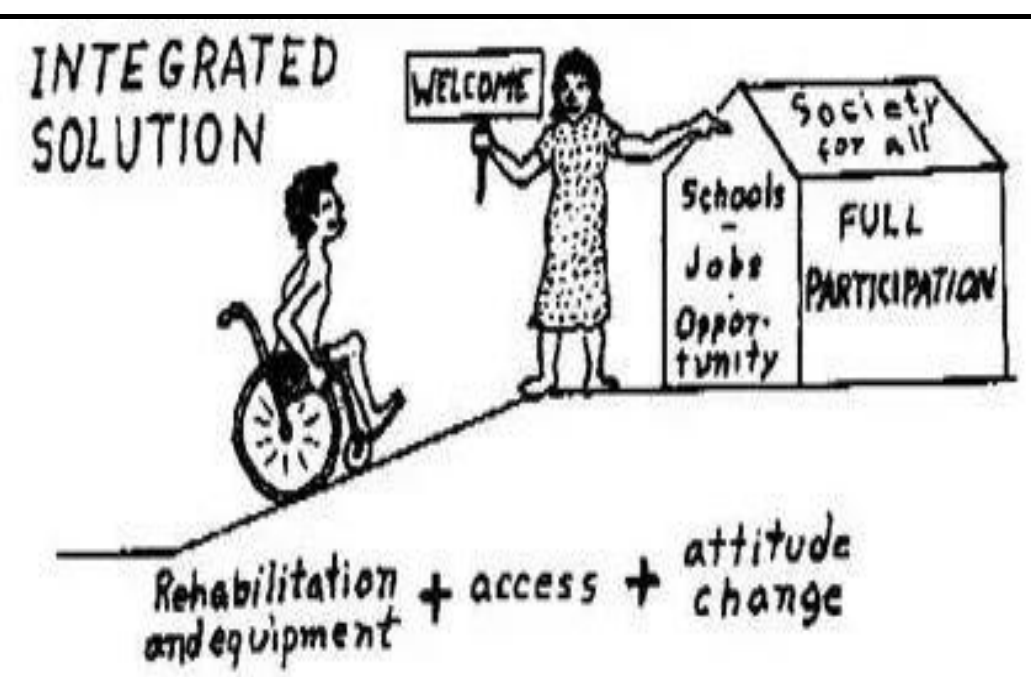

Gambar 2. Solusi Komprehensif untuk Kota Inklusif

\section{Empat Komponen Kota Inklusif dan Indikatornya}

Lalu, bagaimanakah caranya agar kita dapat diajukan konsep yang komprehensif dan integratif? Penulis berpendapat bahwa untuk menyasar tiga hambatan inklusi tersebut (sikap, lingkungan, dan lembaga), sebuah "kota inklusif" wajib memperhatikan empat komponen berikut: (1) Partisipasi difabel; (2) Ketersediaan layanan hak-hak difabel; (3) Pemenuhan aksesibilitas; dan (4) Sikap Inklusif warga kota, baik yang menjabat sebagai aparat pemerintahan maupun warga kota umumnya. Sedangkan sebagai indikatornya, penulis berpendapat bahwa untuk saat ini kita wajib mengacu kepada UU No. 8 tahun 2016 tentang penyandang disabilitas dengan rincian sebagai berikut.

Partisipasi penuh."Partisipasi penuh" artinya difabel dapat berperan serta secara aktif dalam segala aspek kehidupan sebagai warga kota. Dalam hal ini, indikatornya adalah keterlibatan difabel dan atau perwakilan difabel dalam perumusan kebijakan, mulai dari tingkat keluarahan hingga kota. Dalam Pasal UU No. 8 tahun 2016 disebutkan perlunya melibatkan kegiatan sosial, politik (Pasal 75), budaya, dan seni (Pasal 16) dan partisipasi dalam penanggulangan bencana (Pasal 109).

Ketersediaan layanan hak. Adanya upaya untuk menyediakan layanan, fasilitas, program, atau bangunan untuk memenuhi hak-hak penyandang disabilitas sesuai dengan yang dimanatkan UU dan peraturan pemerintah. Indikatornya dapat mengacu ke UU No. 8/2016 tentang Penyandang Disabilitas yang menyebutkan secara terinci 22 hak dasar difabel (Pasal 5), adanya Unit Layanan Disabilitas di bidang pendidikan (Pasal 42), di bidang ketenagakerjaan (Pasal 55), dan adanya unit Layanan Informasi dan Tindak Cepat untuk difabel perempuan dan anak (Pasal 125). Pemerintah dan umum juga wajib menyediakan akomodasi yang layak (Pasal 1-9, pasal 18-b). Selain itu, pemerintah juga wajib menyediakan layanan rehabilitasi sosial, jaminan sosial, pemberdayaan sosial, dan perlindungan sosial (Pasal 90 dan 91).

Aksesibilitas. Artinya kemudahan bagi difabel untuk tanpa hambatan memperoleh manfaat dari sebuah bangunan, fasilitas, layanan, dan program. Secara rinci, Undangundang menyebutkan hal-hal berikut sebagai indikator aksesibilitas ini. Pertama, aksesibilitas untuk memanfaatkan fasilitas publik (Pasal 18-a), aksesibilitas gedung yang 
memiliki fungsi: hunian, keagamaan, usaha, sosial budaya, olahraga, dan khusus (Pasal 98). Kedua, aksesbilitas sarana dan prasarana umum, seperti jalan, jembatan, transportasi, informasi umum, layanan publik yang terjangkau dari segi jarak dan biaya, aksesibilitas dalam layanan peradilan (Pasal 9). Ketiga, aksesibilitas pada sarana dan prasarana penyelenggaraan pemilihan umum, pemilihan gubernur, bupati/walikota, dan pemilihan kepala desa atau nama lain; dan memperoleh pendidikan politik (Pasal 13). Demikian pula, keempat, hak aksesibilitas rumah ibadah (Pasal 14), layanan kebudayaan dan pariwisata (Pasal 85).

Untuk menjamin pemenuhan hak-hak aksesibilitas para difabel, UU menentukan bahwa Pemerintah dan Pemerintah Daerah wajib melakukan audit terhadap ketersediaan fasilitas Aksesibilitas bagi Penyandang Disabilitas pada setiap bangunan gedung (Pasal 99).

Sikap inklusif. Artinya, sikap aparat pemerintahan dan masyarakat umum yang tidak diskriminatif, memberikan pemenuhan, perlindungan, dan penghormatan atas hak-hak difabel. Sikap inklusif tidak disebutkan secara jelas di dalam undang-undang, tetapi dari teori yang disebutkan di awal, jelas bahwa attitude adalah salah satu penghambat dalam proses inklusi. Dalam kasus kota Yogyakarta, hambatan attitudional yang tidak inklusif ini dapat dilihat dalam kasus fasiltas aksesibilitas yang tidak dihormati oleh baik pengambil kebijakan dan masyarakat. Guiding block di Malioboro, misalnya, digunakan untuk parkir dan kaki lima. Mereka tidak tahu, mengabaikan, atau tidak mengerti bahwa guiding block adalah fasilitas inklusi difabel.

\section{KESIMPULAN}

Uraian di atas menunjukkan bahwa tidak mudah untuk mendefinisikan "kota inklusif" dalam konteks lokal karena umumnya secara global "kota inklusif" dipahami berbeda. "Kota Inklusif" lebih dimaknai sebagai inklusivitas ekonomi daripada "inklusifitas dan akses difabel." Upaya tulisan ini untuk mencari akar-akar konseptual dan teoretis, dari teori-teori inklusi-eksklusi sosial menujukkan adanya peluang untuk membuka diskusi lebih lanjut tentang apa dan bagaimana kota inklusif. Kota inklusif dapat didefinisikan sebagai 'kota yang ramah difabel' yang terukur dengan empat indikator yang disusulkan: partisipasi, ketersediaan layanan hak difabel, upaya pemenuhan hak, dan sikap atau budaya inklusif warga kota.

Dengan definisi yang lebih baik, upaya-upaya berbagai kota untuk mewujudkan hak dapat lebih terarah, agendanya terstruktur, dan sasarannya terukur. Jadi, jangan lagi ada simplifikasi bahwa kota inklusif adalah "kota pendidikan inklusif", karena hak-hak difabel yang harus dipenuhi tidak hanya pendidikan, melainkan dua puluh dua hak yang terncatum dalam pasal demi pasal Undang-undang No 8 tahun 2016, yang mencakup hak politik, ekonomi, budaya, hingga olahraga dan seni.

\section{DAFTAR PUSTAKA}

About the Inclusive Cities Project. (n.d.). Retrieved from http://www.inclusivecities.org/about_us/

Barnes, C., \& Mercer, G. (2006). Disability, Work, and Welfare: Challenging the Social Exclusion of Disabled People. Peace Research Abstracts Journal, 43(1).

Barnes, C., Oliver, M., \& Len, B. (2002). Disability Studies Today. Cambridge: Polity Press.

Behrens, M., Bukow, W.-D., Cudak, K., \& Strünck, C. (2016). Inclusive City: Überlegungen Zum Gegenwärtigen Verhältnis Von Mobilität Und Diversität in Der Stadtgesellschaft. Retrieved from http://search.ebscohost.com/login.aspx?direct=true\&scope=site \&db=nlebk\&db=nlabk\&AN=104667 1

Burchardt, T., Le Grand, J., \& Piachaud, D. (1999). Social Exclusion in Britain 1991-1995. SOCIAL POLICY AND ADMINISTRATION, 33(3), 227-244. 
Commentary: What We Mean By 'Inclusive Cities' - The Informal City Dialogues. (2013, January 28). Retrieved 13 January 2017, from https://nextcity.org/informalcity/entry/commentary-what-wemean-by-inclusive-cities

Devlieger, P. (2003). Rethinking Disability: The Emergence of New Definitions, Concepts and Communities. Garant.

Diskusi Desa Inklusi dalam Jagongan Media Rakyat 2016. (2016, April 21). Retrieved 13 January 2017, from http://desainklusi.sigab.or.id/berita/2016/04/21/diskusi-desa-inklusi-dalam-jagongan-media-rakyat2016/

Eide, A. H., \& Ingstad, B. (2011). Disability and Poverty: A Global Challenge. Bristol: Policy Press. Retrieved from http://public.eblib.com/choice/publicfullrecord.aspx?p=726872

Espino, N. A. (2015). Building the Inclusive City: Theory and Practice for Confronting Urban Segregation.

Goltsman, S. M., \& Iacofano, D. S. (2007). The inclusive city: design solutions for buildings, neighborhoods and urban spaces. Berkeley, Calif.: MIG Communications.

Goodley, D. (2011). Disability Studies: An Interdisciplinary Introduction. London: SAGE Publications.

Hadi Rudyatmo Mencanangkan 'Solo Kota Inklusi'. (2013, September 29). Retrieved 13 January 2017, from http://www.pikiran-rakyat.com/pendidikan/2013/09/29/252837/hadi-rudyatmo-mencanangkansolo-kota-inklusi

Hanson, J. (2004). The Inclusive City: Delivering a More Accessible Urban Environment Through Inclusive Design. In Presented at: RICS Cobra 2004 International Construction Conference: responding to change. (2004). York, UK. Retrieved from http://discovery.ucl.ac.uk/3351/

Harris, A., Enfield, S., \& Oxfam GB. (2003). Disability, Equality, and Human Rights a Training Manual for Development and Humanitarian Organisations. Oxford: Oxfam. Retrieved from http://publications.oxfam.org.uk/oxfam/add_info_020.asp

Inclusive Cities: Overview. (2015, October 29). [Text/HTML]. Retrieved 13 January 2017, from http://www.worldbank.org/en/topic/urbandevelopment/brief/inclusive-cities

Kurniawan, H. (2014). Tipologi Renovasi Aksesibilitas Halte Trans Jogja. INKLUSI, 1(1), 1-18.

Laquian, A. A., Tewari, V. K., \& Hanley, L. M. (2007). The Inclusive City: Infrastructure and Public Services for the Urban Poor in Asia. Washington, D.C.; Baltimore: Woodrow Wilson Center Press ; Johns Hopkins University Press.

Maftuhin, A. (2014). Aksesibilitas Ibadah bagi Difabel: Studi atas Empat Masjid di Yogyakarta. INKLUSI, 1(2), 249-268.

Manual Making PRSP Inclusive: 6.1.1 The four models. (n.d.). Retrieved 23 January 2017, from http://www.making-prsp-inclusive.org/6-disability/61-what-is-disability/611-the-four-models.html

Millati, S. (2016). Disability Policy in Indonesia A Critical Discourse Analysis. the University of Sheffield, Sheffield.

parenting- Hak Anak Difabel. (n.d.). Retrieved 20 January 2017, from http://www.republika.co.id/berita/koran/leasure/14/12/16/ngny4a4-parenting-hak-anak-difabel Peringati Hari Disabilitas Internasional, Pemkot Canangkan Empat Kecamatan Inklusi. (2015, June 12). Retrieved 13 January 2017, from http://www.jogjakota.go.id/news/Peringati-Hari-DisabilitasInternasional-Pemkot-Canangkan-Empat-Kecamatan-Inklusi

Pierson, J. (2010). Tackling Social Exclusion. New York, NY: Routledge. Retrieved from http://site.ebrary.com/id/10349708

Salim, I., Syafi'i, M., \& Elisabeth, N. (2015). Indonesia dalam Desa Inklusi. Sleman, Yogyakarta: Sigab. Setidaknya 18.800 orang masih dipasung di Indonesia. (2016, March 21). Retrieved 20 January 2017, from http://www.bbc.com/indonesia/berita_indonesia/2016/03/160320_indonesia_hrw_pasung

Sheppard, M. (2006). Social Work and Social Exclusion: The Idea of Practice. Aldershot, England; Burlington, VT: Ashgate. Retrieved from http://site.ebrary.com/id/10211147

Sosialisasi Pendidikan Inklusif Menuju Solo Kota Inklusi. (n.d.). Retrieved 13 January 2017, from http://www.surakarta.go.id/konten/sosialisasi-pendidikan-inklusif-menuju-solo-kota-inklusi

Suminar, R. E. (2015). Identifikasi Kemudahan Penyandang Difabilitas dalam Melakukan Pergerakan dengan Menggunakan Moda Transportasi. INKLUSI, 2(1), 155-192.

The Greek National Confederation of Disabled People. (2002). Disability and Social Exclusion in the European Union: Time for Change, Tools for Change (Final study report) (p. 78). The Europea Commission. Retrieved from sid.usal.es/idocs/F8/FDO7040/disability_and_social_exclusion_report.pdf

Wendell, S. (1996). The Rejected Body: Feminist Philosophical Reflections on Disability. New York: Routledge.

Whitzman, C. (2013). Building Inclusive Cities: Women's Safety and the Right to the City. New York: Routledge.

Yeo, R., \& Moore, K. (2003). Including Disabled People in Poverty Reduction Work: 'Nothing About Us, Without Us'. World Development, 31(3), 571-590.

Yogyakarta Bertekad Jadi Kota Inklusi. (2016, November 16). Retrieved 13 January 2017, from http://mediaindonesia.com/news/read/77714/yogyakarta-bertekad-jadi-kota-inklusi/2016-11-16 